\title{
ナノスケールの親水部を有する撥水面での凝縮に関する研究
}

\author{
山田 寛 ${ }^{* 1}$ ，草場 彰 ${ }^{* 2}$, 生田 竜也*3，西山 貴史 ${ }^{* 3}$, 高橋 厚史 ${ }^{*}$, 高田 保之*5
}

\section{Study of condensation on hydrophobic surface with nanoscale hydrophilic regions}

\author{
Yutaka YAMADA $^{* 1}$, Akira KUSABA ${ }^{* 2}$, Tatsuya IKUTA ${ }^{* 3}$, Takashi NISHIYAMA ${ }^{* 3}$, \\ Koji TAKAHASHI $^{* 4}$ and Yasuyuki TAKATA ${ }^{* 5}$ \\ ${ }^{*} 1,{ }^{2}, * 3,{ }^{*}$ Department of Aeronautics and Astronautics, Kyushu University \\ 744 Motooka Nishi-ku, Fukuoka 819-0395, Japan \\ ${ }^{* 5}$ Department of Mechanical Engineering, Kyushu University \\ 744 Motooka Nishi-ku, Fukuoka 819-0395, Japan
}

Received 30 September 2014

\begin{abstract}
Water condensation on a hydrophobic surface with nanoscale hydrophilic regions was investigated to reveal the condensation mechanism of submicron-scale droplets. This feature was found on the graphite step-terrace structured surface; step surfaces are more wettable relative to terrace surfaces, and it was precisely characterized using an atomic force microscope. Condensation experiments were conducted using an environmental scanning electron microscope and droplets were observed to line up on preferentially along the graphite steps. Observed droplets ranged from 150 to $300 \mathrm{~nm}$ in diameter and the droplet interval depends on the width of hydrophobic region. The heterogeneous nucleation theory was extended to consider attracted water molecules on hydrophilic step surface, which enable us to explain the current observed result under unsaturated condition. As a result, proposed theory shows qualitatively that narrower hydrophobic region induces short droplet interval. Our suggestion for design the hybrid hydrophilic-hydrophobic surface would enable the development of surface that will perform high heat transfer at dropwise condensation.
\end{abstract}

Key words : Dropwise condensation, Hydrophilic-hydrophobic combined surface, Graphite, Heterogeneous nucleation theory

\section{1. 緒言}

凝縮はループ型ヒートパイプ（McGlen, et al., 2004）や空調システム（Kim and Bullard, 2002）など工業的に幅広く応用さ れているが，特に近年では機器の小型化の観点から，膜状凝縮と比較して 1 桁程度多くの熱を輸送する滴状凝縮が注目を 集めており（Rose, 1998,Carey, 1992）盛んに研究されている. この現象は微細加工技術や撥水性コーティングを駆使して作 製された撥水面で多く見られ（Chen, et al., 2011, Enright, et al., 2012），液滴が表面から離脱する際に再び疑縮面を露出させる ことで滴状凝縮を維持している。しかしながら，一様な撥水面ではエネルギ一障壁が大きいため核生成は発生しにくい. 一 方で親水面からの核生成は発生しやすいことが古典核生成理論より示されているが（Sigsbee, 1969），液滴の離脱は起こり にくいためこれらはトレードオフの関係にある. そのため，両者の特性を生かそうと濡れ性を空間的に制御した表面での 凝縮が研究されている．例えばVaranasi らは, 親水部と撥水部を交互に配置した複合面を用いて実験を行うことで親水面か ら優先的に凝縮が発生することを観察している（Varanasi, et al., 2009）。またWu らは，撥水面に光を照射することで需れ

No.14-00495 [DOI: 10.1299/transjsme.14-00495], J-STAGE Advance Publication date : 12 February, 2015

*1 正員，九州大学大学院 工学府（干819-0395 福岡県福岡市西区元岡 744)

*2 九州大学大学院 工学府

*3 九州大学大学院 工学研究院

*4 正員, 九州大学大学院 工学研究院

*5 正員, フェロー, 九州大学大学院 工学研究院

E-mail of corresponding author: takahashi@aero.kyushu-u.ac.jp 
性を変化させた面で実験を行い同様な結果を得ている（Wu, et al., 2007）。しかし Graham と Griffith は, $10 \mu \mathrm{m}$ 以下の液滴 が滴状凝縮において多くの熱を輸送していると報告しており（Graham and Griffith, 1973），これらの面の親水部分は $10 \mu \mathrm{m}$ 程度と大きいため, 親水部分をさらに小さくしてより小さな液滴の離脱を目指寸必要があると考えられる. そのため, ナノ スケールの親水部分を有する撥水面における凝縮の知見が新たな面の設計に必要となるが，そのような面を作製すること は技術的にも困難であるため実験は行われておらず，凝縮メカニズムの理解は不十分なままである.

本研究ではナノスケールの親水部分を有する撥水面としてグラファイトを用い，あらかじめ表面構造を把握するため原 子間力顕微鏡 $(\mathrm{AFM})$ で詳細に観察した. その後, 試料上での凝縮を環境制御型走査電子顕微鏡（ESEM）て観察し，ナ） スケールの親水部分と凝縮の関係について核生成理論を用いて議論した.

\section{2. 試料の作製と実験方法}

高配向性グラファイト (HOPG) は，炭素の六角形格子が比較的規則正しく層状に重なったもので，その層にほぼ沿う ように辟開した表面はステップーテラス構造をしている. テラス部分にダングリングボンドが存在しないのに対して, ステ ップの断面部分は官能基等が修飾することで需れ性が向上していると考えられる. 両者の濡れ性はHOPG の basal面とそれ に垂直な面の接触角によって評価され，それぞれ $88^{\circ}$ と $76^{\circ}$ と得られた. このことからステップ部分はテラス部分と比較し て親水であることがわかる．試料は粘着テープで剥離した HOPG の薄膜をシリコン基板に転写することで作製した (Novoselov, et al., 2004) ．このときできたステップの高さやテラス部分の幅は, 凝縮との関係を明らかにするためあらかじ め把握する必要がある. 本研究では試料表面の 1 力所に電子線誘起堆積法 (EBID) で局所的にマークを設けることで位置 を決めた後，表面構造を原子間力顕微鏡（AFM; Dimension Icon, Bruker AXS）を用いて詳細に観察した.

凝縮実験は環境制御型走查電子顕微鏡（ESEM; Versa 3D, FEI）を用いて行われた. HOPG の付着したシリコン基板は試 料ホルダーに固定され, ペルチェ素子によって温度制御される. 試料面の温度は $0.0^{\circ} \mathrm{C} に$ 保たれ，真空状態から凝縮が発生 するまで徐々に水蒸気の圧力を増加させた. 観察の際, 電子線による試料の加熱及び夜滴の蒸発を防ぐため, 電子線の加速 電圧と電流はそれぞれ $10 \mathrm{kV}$ と $23 \mathrm{pA}$ に設定した.

\section{3. 実験結果及び考察}

AFM と ESEM の実験は，EBID のマークを目印として行うことで同一の視野を確保している. 図 1 (a) に HOPG の表 面構造を AFM て観察したトポグラフィー像を示しており，表面には高さ $4 \mathrm{~nm}$ 以下のステップ $(S)$ が多数観察された. 形 状の詳細は断面プロファイルにより調査され, $S 1$ の高さは $3.4 \mathrm{~nm}$ と得られた。 この值はおおよそグラファイト層間距離 0.34

(a)

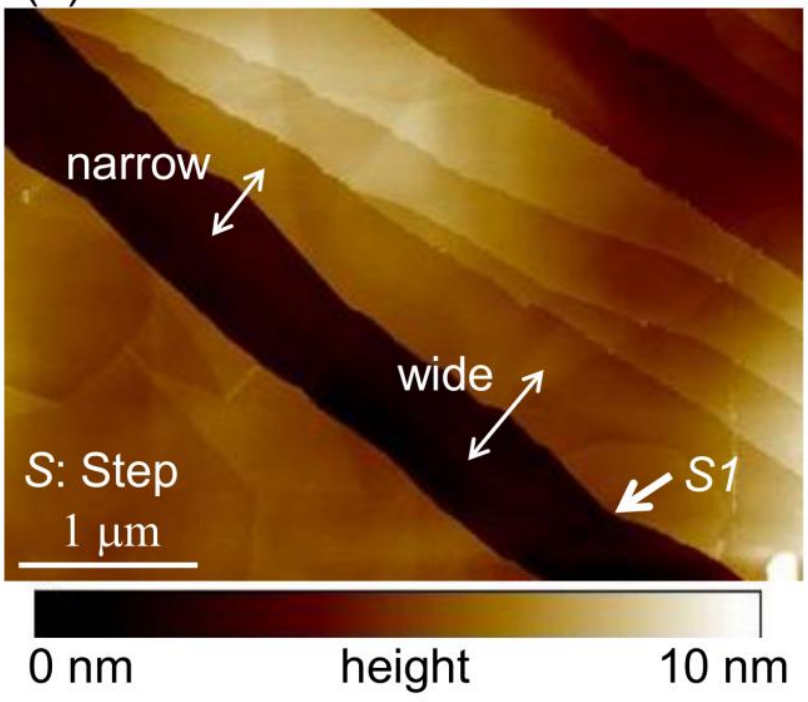

(b)

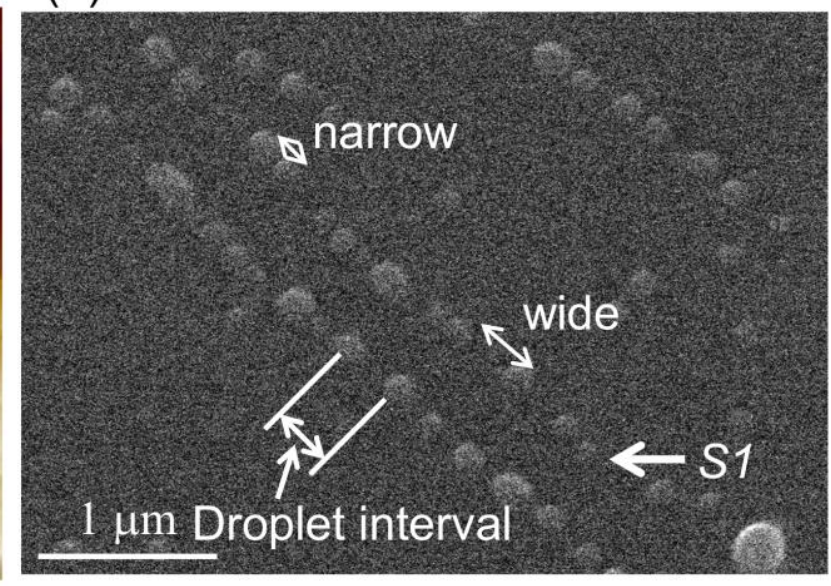

Fig. 1 (a) AFM topographic image of a graphite surface. (b) Water condensation on a graphite surface visualized using an ESEM. (a) and (b) show the same position at the same scale. 

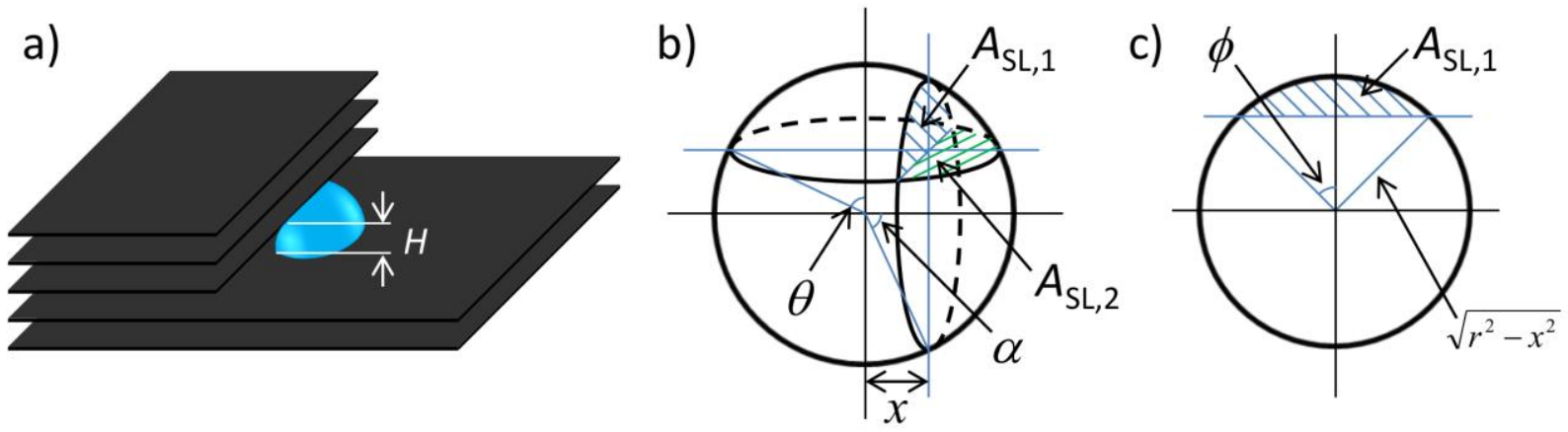

Fig. 2 (a) Schematic of nucleated droplet at graphite step. (b) Schematic of part of droplet. (c) Cross section of droplet with x of horizontal axis.

nm の倍数であった（Ruoff and Lorents, 1995）。図1（b）は凝樎初期の液滴を観察した様子を図 1 （a）と同じ倍率で示して おり，このときの条件は $0.0^{\circ} \mathrm{C}, 560 \mathrm{~Pa}$ であった. つまり，0.0 $\mathrm{C}$ における飽和圧力 $610 \mathrm{~Pa}$ より低い時点で疑樎が発生して おり，液滴はステップに沿って核生成していることが観察された。一方テラス上では液滴が観察されていないため，ステ ップの存在が凝縮の初期過程に影響していることがわかる．観察された液滴直径は 150 から $300 \mathrm{~nm}$ であり，図 1 (a) に示 されているようにテラスの幅が広いほど，図１（b）に示液滴間䛿広くなることがわかった．また，この実験条件では 装置の分解能に制限があるため，150 nm より小さい液滴を観察することはできなかった，そのため，核生成後の液滴が成 長した結果を観察しているものと考えられる.

これまでの親水撥水複合面の凝縮実験において，凝縮初期のメカニズムは理解されていない，また，ステップに核生成 した液滴の形状は観察することができていないため，図 2（a）に示寸ように cap-shape（球の上部を切り取った形状）の一 部がステップに付着した形状であると仮定する. これは, 平坦な面と比較して $90^{\circ}$ に近い角度を持つ角では, 核生成に必要 なエネルギーが少なく液滴が生成されやすいためである (Chakraverty and Pound, 1964).ここで核生成した液滴はステップ, テラスの両面に広がると予想される. しかしステップ面では, グラフェンのエッジでピニングが発生すると予想されるため 三相界線は動か寸゙，テラス面にのみ液滴が広がると考えられる．このような仮定をおいて実験結果を説明するため, 不均質 核生成理論（Carey, 1992, Sigsbee, 1969, Chakraverty and Pound, 1964）を適用して考察する．このとき液滴の有する自由エネル ギー $\Delta G$ は式（1）で表され

$$
\Delta G=\Delta G_{v} V_{d r o p}+\left(\gamma_{S L, 1}-\gamma_{S V, 1}\right) A_{S L, 1}+\left(\gamma_{S L, 2}-\gamma_{S V, 2}\right) A_{S L, 2}+\gamma_{L V} A_{L V}
$$

$A ， V_{d r o p}, \Delta G_{v}$, は土それぞれ面積，液滴の体積，単位体積当たりの液体の自由エネルギー，表面張力を示している．添え字 の $S, L, V$ はそれぞれ固相，液相，気相を意味し，1,2 は親水面と撥水面を示している. ステップ面と液滴の接触面積 $A_{S L, 1}$ は図2（b）の斜線部で示され，断面形状は図2 (c) に示されている. この面積は式 (2) で表され，

$$
A_{S L, 1}=\left(r^{2}-x^{2}\right) \phi-r \cos \theta \sqrt{r^{2}-x^{2}-r^{2} \cos ^{2} \theta}
$$

ここで $r ，$ 日はそれぞれ液滴の曲率半径とテラス面での接触角であり， $x$ とфはそれぞれ

$$
x=r \cos \alpha
$$

$$
\phi=\cos ^{-1} \frac{\cos \theta}{\sin \alpha}
$$

と示される. ステップ面での接触角 $は$ は三相界線がグラフェンのエッジでピニングされると予想されるため, 線張力に影響 されにくくなると考えられる. しかしながら接触角を予測することは困難であるため, ここではバルクの接触角と同等であ ると仮定して議論する.一方テラス面での接触角 $\theta$ は, 液滴の曲率半径とステップ面に付着した液滴の高さ $H$ を用いて式 (5) より求めることができる.

$$
\theta=\cos ^{-1} \frac{r \sin \alpha-H}{r}
$$


しかし，液滴の高さは観察することができていない．また， $H$ が高い場合，核生成した液体の量が多くなり，凝縮の初期過 程における液滴の間隔を説明することができなくなる.さらに, 核生成はステップ下部の角から発生しやすいと考えられて おり，このとき液滴はグラフェンのエッジでピニングされると予想される. そのため $H$ はグラフェン 1 層分の厚さである $0.34 \mathrm{~nm}$ と仮定して計算した.
テラス面と液滴の接触面積を示寸 $A_{S L 2}$ は式
(2) から
（4）と同様に考えることで式
（6）のように得られる.

$$
A_{S L, 2}=r^{2} \sin ^{2} \theta \cos ^{-1} \frac{\cos \alpha}{\sin \theta}-r^{2} \cos \alpha \sqrt{\sin ^{2} \theta-\cos ^{2} \alpha}
$$

気液界面の面積は弧の長さを積分することで得られ式（7) で示される.

$$
A_{L V}=\int_{r \cos \alpha}^{r \sin \theta} 2 \sqrt{r^{2}-x^{2}} \cos ^{-1} \frac{r \cos \theta}{\sqrt{r^{2}-x^{2}}} d x
$$

また，液商の体積は面を積分することで式（8）より得られる.

$$
V_{d r o p}=\int_{r \cos \alpha}^{r \sin \theta}\left(r^{2}-x^{2}\right) \cos ^{-1} \frac{r \cos \theta}{\sqrt{r^{2}-x^{2}}}-r \cos \theta \sqrt{r^{2} \sin ^{2} \theta-x^{2}} d x
$$

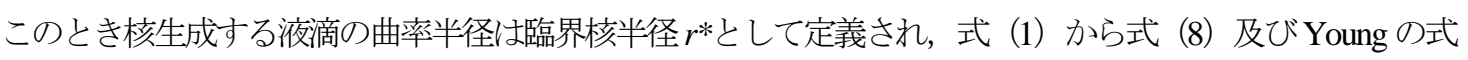

$$
\cos \theta=\frac{\gamma_{S V}-\gamma_{S L}}{\gamma_{L V}}
$$

を用いて自由エネルギーの極值を式（10）で計算し，

$$
\frac{\partial \Delta G}{\partial r}=0
$$

$r$ について整理することで得られる.ここで $G_{v}$ は式（11）で示され

$$
\Delta G_{v}=-\rho_{l} k T \ln \left(P / P_{0}\right)
$$

$\rho_{l}, k, T, P, P_{0}$ はそれぞれ液体内の分子数密度, ボルツマン定数, 固体面の温度, 蒸気圧, 温度 $T$ における飽和蒸気圧を 示している. しかしながら，この理論は式 (11) からわかるように過飽和状態で成立するため, 今回の実験条件にそのまま 適用するとこはできない，そのため図 3 （a）に示寸ように，グラファイトステップの親水部分に水分子が引き寄せられる ことで表面近傍の圧力が増加すると仮定して理論の拡張を提案する. 引き寄せられた水分子の体積 $V_{a t}$ は

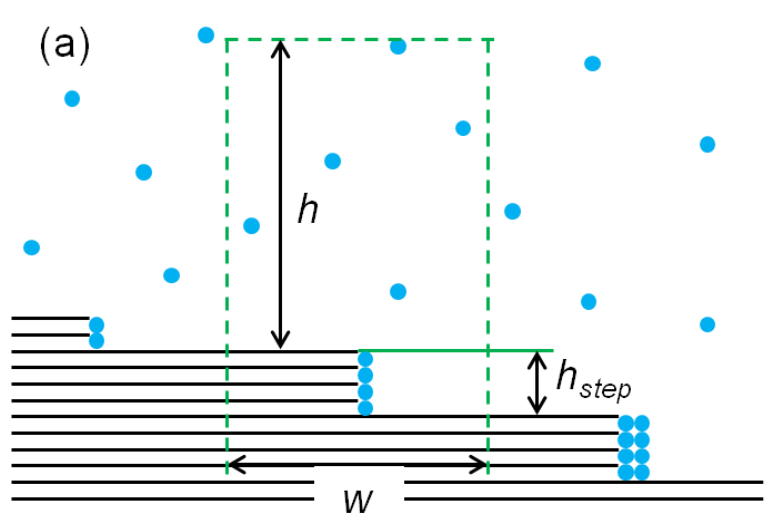

(b)

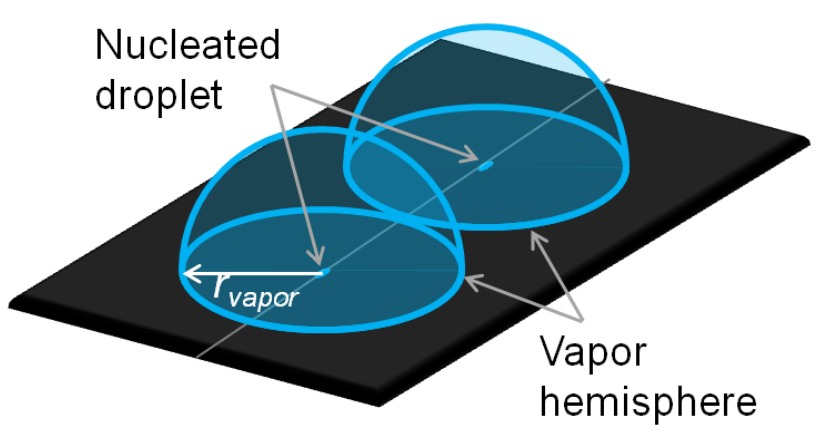

Fig. 3 (a) Schematic image of attracted water molecules on graphite steps. (b) Schematic image of nucleated droplet and hemisphere of vapor molecules within a mean free path of the nucleation site on the surface (see text for details). 


$$
V_{a t}=l \times h_{\text {step }} \times t \times v_{0}
$$

で示され， $l, h_{s e p}, t, v_{0}$ はそれぞれステップの長さ，ステップの高さ，固体面に引き寄せられた水分子の面密度 $\left[1 / \mathrm{m}^{2}\right]$ 及び 水分子の直径を $0.31 \mathrm{~nm}$ としたときの分子 1 個の体積を示している. $t$ は各ステップ内では均一であると仮定し, 圧力の上 昇に寄与寸る分子のみ考える. 一方で，これらの水分子が圧力として作用する表面近傍の体積は

$$
V=h \times l \times w
$$

で定義され， $h$ は引き寄せられた分子が，固体表面から空間に向かって等方的に平均自由行程分移動した時の平均高さ， $w$ は対象とするステップの両側にあるテラス幅の半分の和として定義される. そのため, 水分子は引き寄せられたステップで の核生成にのみ影響を与えると考える. 本実験条件において $h$ は数十 $\mu \mathrm{m}$ であるため, ステップの高さは無視できる. 圧力 の増加分 $\Delta P$ は，引き寄せられた水分子の体積と表面近傍の空間の体積を用いて式（14）のように計算される.

$$
\Delta P=\frac{N_{a t}}{N_{A}} \frac{R T}{V}
$$

ここで $N_{A}$ と $R$ は 1 モル当たりの分子数と気体定数を示しており， $N_{a t}$ は

$$
N_{a t}=\frac{V_{a t}}{v_{0}}
$$

である. このように分子が親水面に引き寄せられて表面近傍の圧力が増加すると仮定すると, 式 (11) は以下のように修正 される.

$$
\Delta G_{v}=-\rho_{l} k T \ln \left(\frac{P+\Delta P}{P_{0}}\right)
$$

核生成した液滴はピニングの影響によりステップの高さと比較して低くなり,このときの体積は引き寄せられた水分子を 考慮して理論を修正することで，先に述べたように式（8）から得られる．また，このとき核生成した液滴の $r$ *は，おおよ そ $25 \mathrm{~nm}$ と見積もられる. この液滴を構成する水分子が図 3 (b) に示寸ような半球状に分布した蒸気の領域から供給され ると考えると，この体積は式（17）で表され，

$$
V_{\text {vapor }}=V_{\text {drop }} \times \frac{\rho_{l}}{\rho_{v}}
$$

ここで $\rho_{v}$ は蔒気の分子数密度を示している. この蒸気の半径は, 式 (1) と式（16）から得られる $r$ *を与えることができれ ば式（18）のように得られ，

$$
r_{\text {vapor }}=\sqrt[3]{\frac{3 V_{\text {vapor }}}{2 \pi}}=\sqrt[3]{\frac{3 \frac{\rho_{l}}{\rho_{v}} \int_{r^{*} \cos \alpha}^{r^{*} \sin \theta}\left(r^{* 2}-x^{2}\right) \cos ^{-1} \frac{r^{*} \cos \theta}{\sqrt{r^{* 2}-x^{2}}}-r^{*} \cos \theta \sqrt{r^{* 2} \sin ^{2} \theta-x^{2}} d x}{2 \pi}}
$$

図 3 (b) に示寸半球状の蒸気領域が互いに重ならないと仮定すると, 隣り合う半球同士の半径の和を最小の液滴間隔とし て予測することができる. 式（18）で得られた液滴間隔と $3.4 \mathrm{~nm}$ のステップでの実験結果の比較を図 4 に示す。この結果 より, テラス幅が狭くなるにつれて液滴間隔が短くなる傾向を, ステップに水分子が引き寄せられると仮定することで定性 的に説明することができた. しかしここでは液滴間隔を説明するため水分子が多数引き寄せられていると仮定しているの みであり，測定することはできていないため定量的な議論はできない. また，ここで拡張した理論は最小の液滴間隔を予測 しているが, 実際の液滴間隔はこれより広くなる可能性がある. その原因として, ESEM で観察を行う前に液滴同士が合体 してしまうことや，局所的に濡れ性の良い部分で核生成寸ることによって液滴間隔が広くなってしまうことが考えられる. しかし，そのようなデータ点はプロットから除外している. 


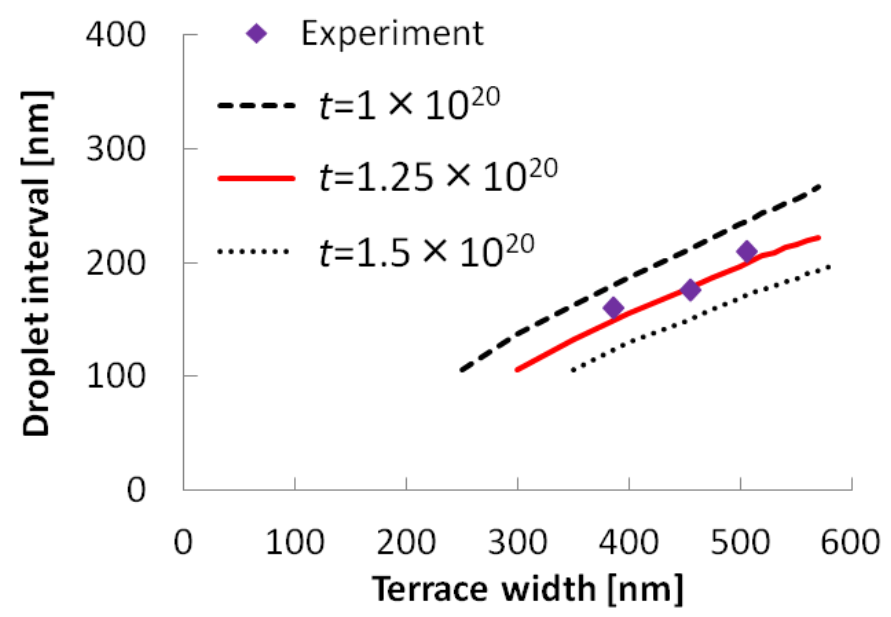

Fig. 4 Comparison of experimental and theoretical results of droplet interval using surface density of attracted molecules on step height $h_{\text {step }}$ of $3.4 \mathrm{~nm}$.

実験及び拡張した理論で示したように，狭いテラス幅ほど短い液滴間隔が得られることがわかった. また, 水分子が親水 部分に引き寄せられると考えることでこの結果を定性的に説明することができた. 得られた結果より滴状凝縮の熱輸送性能 を向上させるためには，複合面内の親水部分同士の間隔を狭くすることが有用であると言える．今後は液滴の合体や離脱 を考慮して，熱輸送を促進する表面構造を決定していく必要がある.

\section{4. 結言}

本研究では，表面にナノスケールの親水部分を有する比較的撥水な面である HOPG を用いて凝縮実験を行った. この表 面構造は AFM を用いてあらかじめ詳細に観察され，核生成直後の様子を ESEM を用いて観察することで親水撥水複合面 と凝縮の関係について調査した，観察された液滴は HOPG 上のステップに沿ってできており，液滴間隔はテラスの幅に依 存していた. この結果を説明するため, 親水部分に蒸気中の水分子が引き寄せられると仮定することで不均質核生成理論を 拡張し，テラス幅が狭いほど液滴間隔が短くなる結果を定性的に示した. ここで得られた結果は, 狭いテラス幅を有する親 水撥水複合面で多くの液滴が核生成されることを示しており，核生成時の接触角や表面の濡れ性を考慮して複合面を設計 することで，滴状凝縮の熱輸送性能の向上が期待できる.

\section{謝辞}

本研究は JSPS 特別研究員奨励費 25-4996 及び JST-CREST の助成を受けたものである.

\section{References}

Carey, V. P., Liquid-vapor phase-change phenomena: An introduction to the thermophysics of vaporization and condensation processes in heat transfer equipment, Taylor and Francis, New York (1992).

Chakraverty, B. K, and Pound, G. M., Heterogeneous nucleation at macroscopic steps, Acta Metallurgica, Vol. 12 (1964), pp. 851-860.

Chen, X., Wu, J., Ma, R., Hua, M., Koratkar, N., Yao, S. and Wang, Z., Nanograssed micropyramidal architectures for continuous dropwise condensation, Advanced Functional Materials, Vol. 21 (2011), pp.4617-4623.

Enright, R., Miljkovic, N., Al-Obeidi, A., Thompson, C. V. and Wang, E. N., Condensation on superhydrophobic surfaces: the role of local energy barriers and structure length scale, Vol. 28 (2012), pp.14424-14432.

Graham, C. and Griffith, P., Drop size distributions and heat transfer in dropwise condensation, International Journal Heat Transfer, Vol. 16 (1973), pp.337-346.

Kim, M. H. and Bullard, C. W., Air-side performance of brazed aluminum heat exchangers under dehumidifying conditions, International Journal of Refrigeration, Vol. 25 (2002), pp.924-934. 
McGlen, R. J., Jachuck, R. and Lin, S., Integrated thermal management techniques for high power electronic devices, Applied Thermal Engineering, Vol. 24 (2004), pp.1143-1156.

Novoselov, K. S., Geim, A. K., Morozov, S. V., Jiang, D., Zhang, Y., Dobonos, S. V., Grigorieva, I. V. and Firsov, A. A., Electron field effect in atomicaly thin carbon films, Science, Vol. 306 (2004), pp. 666-669.

Rose, J. W., Condensation heat transfer fundamentals, Chemical Engineering Research and Design, Vol. 76 (1998), pp.143-152.

Ruoff, R. S. and Lorents, D. C., Mechanical and thermal properties of carbon nanotubes, Carbon, Vol. 33 (1995), pp.925-930.

Sigsbee, R. A., in Nucleation, edited by Zettelmoyer, A. C., Marcel Dekker, New York (1969).

Varanasi, K. K., Hsu, M., Bhate, N., Yang, W. and Deng, T., Spatial control in the heterogeneous nucleation of water, Applied Physics Letters, Vol. 95 (2009), 094101.

Wu, Y., Kouno, M., Saito, N., Nae, F. A., Inoue, Y. and Takai, O., Patterned hydrophobic-hydrophilic templates made from microwave-plasma enhanced chemical vapor deposited thin films, Thin Solid Films, Vol. 515 (2007), pp.4203-4208. 